\title{
Quality perception among university students and influence on Islamic culture on it: a case study
}

\author{
Shatha Azat Hawarna \\ Hamdan Bin Mohammed University, \\ UAE-Dubai, P.O. Box 97972, Dubai \\ E-mail: Sh_hawarna@yahoo.com
}

\begin{abstract}
This study aims to explain the quality management services in Islam perspective through interviewed sample of university students. From this sample, we can find out if people understand the quality management services concept based on Islam perspectives as well the concept driven from Western countries. This study implements a qualitative method, using interviews. A total of seven postgraduate students were interviewed from different Kulliyyahat at International Islamic University Malaysia (IIUM). Different procedures and tools are used to carry out a rigorous qualitative analysis. The study reveals many interviews. Most interviewees have basic information related to quality and need more awareness on its history and roots. This research will provide undeniable evidence that Muhammed (SAW) was the core of quality and will discuss it in two pronged:

1 quality management services as a standard concept in its generic form

2 quality management services concept based on the holy Qur'an and Sunnah.

Keywords: management; quality management; quality management services; quality management in Islam perspective; quality management services in Islam perspective.

Reference to this paper should be made as follows: Hawarna, S.A. (2011) 'Quality perception among university students and influence on Islamic culture on it: a case study', Int. J. Arab Culture, Management and Sustainable Development, Vol. 2, No. 1, pp.72-82.

Biographical notes: Shatha Azat Hawarna received her BA in Business Administration with high distinction from UAE University and Master degree with high distinction from Wollongong University, Australia. She worked in Hamdan Bin Mohammed University from 2003-2009 as the Centre Manager of excellence in Education, and from 2009 till now as the Manager of Learners Accessibility. She is a PhD student in IIUM - The Kulliyyah of Business and Economy.
\end{abstract}

\section{Introduction}

Quality management services are considered an effective management tools in supporting and improving organisation performance. The most successful and inventive organisations are concentrated in using quality management services as model forward to excellence. 
Nowadays, new organisations have become very interested in applying the concept of quality management services in all divisions with variety models of quality. Without any knowledge that this concept came from Islam.

Quality management services concepts are implanted in most of the developed countries. This concept is not a new concept in Islam. As a Muslim, our religion encouraged us to perform our works in perfect way and Allah will reward those people who do a good performance. There are a lot of evidences in the Glorious Qur'an and in Sunnah. For example, Allah said in the Sort Alnamil (88) that "The artistry of God, who disposes of all things in perfect order" (Shafi, 1980).

Therefore, this study undertakes to increase awareness and people's understanding that the quality management services criteria's came from Islam concept which began before 14th century and not as the Western countries claimed that they are the pioneers in this field. This research will try to fill out the gap and show the literature review related to this topic.

\section{Literature review}

This case study will view the meaning of quality management services and quality management services in Islam perspective. The aim is to find out if people were aware about these meaning.

We can say that management is the process of getting things done through other people, which mean that there are management functions. These functions are simply parts of a manager's job in any organisation. The organisations constitute groups of people endowed with diverse capabilities and interest, working towards achieving a common vision through a set of goals (Al-Habshi and Hassan, 1998). Functions of management in any organisation include planning, organising, motivating, leading and controlling. Islam does not differ with the above functions of management. In Islam there are planning, organising, motivating, leading and controlling (Mohiuddin, 1997).

Work motivation is one of the most serious problems being faced by almost all types of organisations, especially the industrial and business organisations. Managers and administrators frequently complained that their employees do not want to work (Faridi, 1997). We can find that work motivation is clear in Islamic perspective because Muslims knows very well that Allah sees all of us and rewards the honest and hard working ones. The Prophet (SAW) has taught us that every human endeavor is an act of worship and charity. Thus a Muslim engaged in work knows that through his work, he is worshipping his Lord and this is a powerful motivator in itself irrespective of any material gain (Ahmad, 2006). However, there are three states or stages of the development of the human soul or nafs:

1 ammarah which is prone to evil, and, if not checked and controlled, will lead to perdition

2 lawwamah, which feels consciousness of evil, and resists it, asks for Allah's grace and pardon after repentance and tries to amend; it hopes to each salvation

3 mutma'innah, the highest stage of all, when the soul achieves full rest and satisfaction after aql (intellect) has checked the evil tendencies of man. 
The level if taqwa depend on these three states of the soul (Beekun, 1981).

Obviously, quality management is a key to organisational success, and as a certain management style shows its effectiveness, more people tend to explore and learn about it. For example, great interest exists among managers from around the world to learn about Japanese management because of the great success of Japanese companies. We can say the meaning of quality management, as Juran mentioned in his book that the quality is fitness for use. Juran is known as the father of quality and he also considered two aspects of product quality. One is freedom from deficiencies and the other is product features (Stephens and Juran, 2005). Earlier, quality improvement was primarily focused on reducing deficiencies but has developed to include quality services such as accounting, invoicing, communications, etc.

The concept of quality is an essential aspect of effective management and its appreciation highly depends on prevalent values (Ahmad, 2006). Muslim societies have yet to make their contribution toward quality management system. So, we can identify Islamic Management of Excellence as Al-Habshi and Ghazali (1994), explains the importance of a stable family institution which means a good home for one's family, instead of a house to live in. In addition, we should also realise that creating a sustainable society requires a multidimensional approach to human civilisation rather than just focusing on economic success and prosperity.

There is quality management in services and quality management in products both of them interest to provide good standard of quality. Our study will focus on quality management services.

Edward Deming, an eminent statistician, was one of the first to recognise the importance of service as a vital component of quality. He is credited with having taught the Japanese how to create and deliver quality while much of his work centred on products; his vision of quality is very broad in scope and extends beyond statistical quality control making his ideas relevant to any area of services quality.

Deming's developed fourteen points outlining what an organisation has to do to achieve quality. Total quality management (TQM) was originally developed by an US statistician; TQM emphasise client feedback, performance monitoring, continuous improvement and worker participation. Edwards Deming focus on create constancy of purpose toward improvement of product and service with the aim to become competitive, stay in business and provide jobs (Chakrapani, 1991).

\section{Method}

\subsection{Population and sample}

The sample consisted of many postgraduate students. Individuals interviewed had been conducted through students from different Kulliyyahat. It was important to meet those students to measure people's awareness of quality in Islam. This case study achieved its result through seven participants. The sample size was not determined at the initial stage of the study, where recruitment of participants continued until the sensed that adding any sample will not add any value to our study. 


\section{Methodology}

The general goal is to find out the meaning of quality in Islam through using qualitative approach. An interview was built with several questions. The interviewee's were asked to define quality management services and quality services in Islam perspective. The following are the questions used in the interviews: What is the meaning of quality management? What is a quality management service? What is the meaning of quality management in Islam? What do you think about the meaning of quality management services in Islam?

The strength of this study is that the interviewees used their own words. The average duration of interviews was between thirty to forty five minutes. Semi-structured interviews were conducted face to face with postgraduate students from different Kulliyyahat. The interviewees were given the option of meeting at the IIUM library, at the classroom, or any other location that was fitting for them. Interviews were: recorded, transcribed, coding and detailed notes were taken during the interviews.

After each interview, notes were taken and added details based on recorder and memory of the interview. The transcripts were not sent to the participants to respond with comments and/or corrections because of time limitation. Data analysis began after the first interview. Codes were identified immediately and then revised as more interviews were conducted. Twelve meaning units came into view from participants explaining the meaning of quality management services and quality management services in Islam, then began to relate the units to each other.

\section{Data analysing and resulting}

Four postgraduate students were from Economy and Management Kulliyyah, one participant from Education Kulliyyah, one from Kulliyyah of Islamic Revealed Knowledge and Human Sciences, and one from Kulliyyah of Information, Communication Technology. All participants chose to be interviewed at the library in IIUM (in a library first, third floor or in classroom). By the seventh interview, no new thematic information was presented by participants.

At that point, our sample reach to saturation, which means new interviews will not be add any new value for our study. A sample size of seven participants gave a clear situation about the people understanding of the quality management services in Islam.

Due to reasons of confidentiality, names of participants were not reported in the research. Participants were two females and five males with age above twenty nine years.

The following themes emerged and are reflected in direct quotations.

\subsection{Talking about the meaning of quality management concept}

During the interviews, it was clear that all of participants were aware about the meaning of quality management and they identified it in different concepts. All of these definitions were correct or at least near from the concepts mentioned in literature review. The following are some of their understanding about the quality management concepts, where we can observe that all of these definitions were close from each other. 
"I think the quality is a system, it means that the quality related to managements sector in any organization as financial, HR, IT (all systems in the organization management)".

"Quality management is a management that is concerned with performances evaluation in productions or services additionally related to how to develop the field that looks for consistent achieves the products and services".

"I think quality management related to things done in a good way or in specific feature that the customer demands in order to reach satisfaction, in other wards we can say the quality is a standards which mean each process should follow standards procedure".

"I think the quality is the standard which means if the customers are satisfied with the products or services that indicates they reach to the standards".

To get a clear meaning I asked one of the participants what he meant by standards? He answered that "Standard is a specific level if the organisation reaches to this level in quality it means the organisation is excellence in quality" and as he mentioned some of people expert in this field put these standards but he didn't know exactly from where those experts.

"Quality management has a wide meaning of quality in services sector than manufactories, because when talking about quality in services it meets and maybe exceeded people expectations. This can be found clearly from services done in airlines, hotels and education institutes".

"I think quality management is considered from four main components: quality planning, quality control, quality assurance and quality improvement. In addition, we can say quality management is focused not only on product and its service quality, but also the means to achieve it. It uses quality assurance and control of processes as well as products to achieve more consistent quality".

"Actually quality management is to be sure that the production procedure of management is done to the most powerful and advance management techniques. This means that you have to produce and manage the firm to compete other companies around the worlds".

Based on their different definitions and comparing with literature review related to definition of quality management we can say that twelve meaning units came into view from participants who explain the meaning of quality management such as quality is system, standard, things done in a good way, good performance, ... etc. and we can say all participants were aware about the meaning of quality management.

\subsection{The meaning of quality management services}

All participants were aware about the meaning of quality management services because our samples were postgraduate students and they were dealing with many organisations that provide services such as hospitals, education institutes, financials... etc. their answers were as follows:

"I think quality management services is a value add to the products such as services after sell the products. So, quality services are services when it meet or exceed the expectation of the customers e.g., some organizations provide services only such as hospitals, education, and so on. Therefore; quality services are related to these organizations". 
"From my point of view, quality management services consistent monitoring, developing, managing and methods to achieve desired results. It is an auditing process that tries to extract the best and most and we can find quality management services in any organization such as the services after selling the product or the originations provide services e.g., hospitals, banks....etc efficient to achieve goals".

"The meanings of quality management services as a short definition we can say that quality services related to organization provide services and seek to let the customers satisfy and feel happy with these services".

"Quality management services are related to organizations that provide services e.g., education, health sector, banks.... etc".

"Quality management services have a wide meaning of quality in services sector than manufactories, because when we are talking about quality in services it meet and maybe exceeded the people expectations. This can be found clearly from the services done in airlines, hotels, education institutes".

"Quality management service is the ability to provide different priority to different applications, users, or data flows, or to guarantee a certain level of performance to a data flow. In my opinion, for real-time streaming multimedia applications quality of service guarantees are important if the network capacity is insufficient, such as voice over IP, online games and IP-TV, since these often require fixed bit rate and are delay sensitive, and in networks where the capacity is a limited resource, for example in cellular data communication".

"I think quality management services mean managers and employees make sure and follow specific steps to reach the highest performance in producing the services and there are two main reasons to achieve the targets. Firstly; achieve customer's satisfaction and secondly; increase the market share with a good quality advantages".

To get a clear answer I asked one of the participants to explain what he means by market share and he said:

"I meant that when increasing the market share you will provide a good quality services to encourage all people to be your customers by having excellent level of quality services".

Most of interviewee's answers were close from each other's but only one participant his answer was totally different and he said:

"Quality Management Services: consistent monitoring, developing and managing means and methods to achieve desired results. It is an auditing process that tries to extract the best and most efficient means to achieve goals".

The participant focus in the previous definition on the task of monitoring and evaluation the process to achieve desired results because I think this refer to the common knowledge that most of people do well if they know that somebody evaluate their work.

Related to this issue, we can ask this question, how many organisations that talk about quality will support employees who provided quality, but when doing so this will not be profitable to the organisation. For instance, if a bank employee spends 30 minutes with a customer who is not particularly profitable but who has a problem, will the bank manager appreciate the employee's efforts? Many organisations which talk about service quality fail to provide it because they use the concept selectively without constancy of purpose.

But we still have a question related to this purposes. Do all employees know the purpose? How do you know it is understood by all employees? Quality services from 
Islam perspective can answer this question because in Islam the manager should be role models for all employees. So; they can understand the purpose and the mission of the organisation from the manager attitudes and from his instructions as a leader of the organisation and we can find this clear from Al Hadith that Prophet Mohammed (SAW) said:

\footnotetext{
"Pray as you have seen me praying, and when it is the time of prayer, one of you should pronounce the call (Adhan) for the prayer and the eldest of you should lead the prayer".
}

\subsection{The meaning of quality management in Islam}

Most of participants were not aware enough about this concept, they knew very well the meaning of quality management but they do not know that the quality came from Islam and Prophet Mohammed (SAW) is the father of quality and not as most people knows that Juran is the father of quality. Most of Ahadith in Sunnah mentioned the meaning of quality management in different ways and Prophet Mohammed (SAW) created the standards through explaining the Qura'an and if any one implemented these standards will get satisfaction and reward from Allah. The interviews answers were as follow:

"I think the quality management in Islam it means perfection to make the product services as perfect as possible and we can see this meaning clear from Hadith of Prophet Mohammed (pbuh) said:

"Allah loves that if one does a job he perfects it".

The same meaning required for quality concept, to do the thing without any mistake.

"Quality in Islam can be well explained from this Hadith:

"He who acted dishonestly towards us is not of us".

Which means everything should be standard and truth in Islam and does not any deception.

"The same meaning of quality management but based on Islamic perspective of performance. In my opinion; Islamic is what is allowable or prohibited. We can say the quality in Islam is to get Allah satisfaction. So, we have to do services in Islam with higher standards and we have to care about how Allah sees these things done. Also, we have doing everything which we feel that Allah see us. In addition, I think the quality was exists before Islam but with Islam quality it became more completely".

"I am not sure about that but I can say quality management in Islam can be found from the Hadith, that Prophet Mohammed, Messenger of Allah, sallallahu 'alayhi wasallam, said:

Verily Allah the Exalted is pure. He does not accept but that which is pure.

"Quality management in Islam clearly mentioned in the Hadith:

The Prophet Mohammed (SAW) said, 'The truthful trustworthy merchant is with the Prophet (SAW) the True ones and the martyrs (on the Day of Resurrection).

"I believe that the concept of quality in Islam is different from other quality concept. This is in regards to the use of quality in managerial and economic science which is totally different than when it is used in Islam. So, in Islam you have to do all activities in a good way and in high performance to seek Allah 


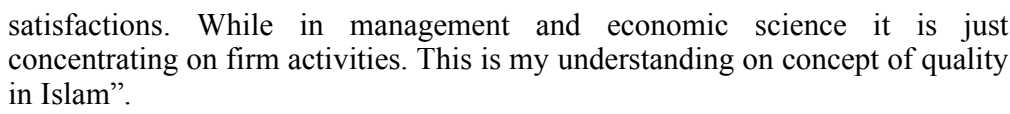
concentrating on firm activities. This is my understanding on concept of quality in Islam".

From the previous answers we can say that most of the interviewees used this Hadith to explain and support their answers that Prophet Mohammed (SAW) said:

"Allah loves that if one does a job he perfects it".

They used the previous Hadith in question three and four as evidence to clear their responds.

The same meaning used in current time but in a different concept under the meaning of do the right thing with zero defect (Stephens and Juran, 2005). This means you have to do all things without any mistake.

Conversely, the standards of quality came and rooted from Islam concept and we can find the evidence as we mentioned before from this Hadith.

Allah's Apostle entered the mosque and a person followed him. The man prayed and went to the Prophet and greeted him. The Prophet returned the greeting and said to him, "Go back and pray, for you have not prayed".

The man went back prayed in the same way as before, returned and greeted the Prophet who said, "Go back and pray, for you have not prayed." This happened thrice. The man said, "By Him Who sent you with the Truth, I cannot offer the prayer in a better way than this. Please, teach me how to pray." The Prophet said, "When you stand for Prayer say Takbir and then recite from the Holy Qur'an (of what you know by heart) and then bow till you feel at ease. Then raise your head and stand up straight, then prostrate till you feel at ease during your prostration, then sit with calmness till you feel at ease (do not hurry) and do the same in all your prayers.

So, the Prophet Mohammed peace be upon him (SAW) does not agree about the way that the person pray because the person does not reach the standards to let Allah accepted the pray.

With the same concept the quality management established by standards and if any organisation implements these standards will get quality rewards and excellence degree which can enhance the reputation.

\subsection{The meaning of quality management services in Islam perspectives}

For this question most of participants used Glorious Qur'an and Sunnah to support their answers.

"I think no difference between quality services and quality in Islam services because from my understanding, Islam enhance to do our job perfectly which lead to a high quality services of products".

"I think this question related to the previous question. I think the quality management services in Islam is the same as in the quality service concept. However; these services and methods has to be Shariaa compliant and the targeted quality has to adapt the Shariaa context in all process and procedure".

"In my opinion, quality management services in Islam it depend on internal feeling which call "Niyah" seeking for good services concerning reward from Allah. And we can find this meaning from "Hood Surah", Ayah 15. 
"Whoso desireth the life of the world and its pomp, we shall repay them their deeds herein, and therein they will not be wronged".

"Quality management services are related to organizations provides services. In Islam if you provide services to customers you have to smile in front of customers. Allah's Messenger (SAW) said, "Your smile before your brother is a Sadaqah for you".

Different words with the same meaning, the participants said:

"I think this concept related to services when you do work and provide services you has to great your customers. Also, Islam said you have to share full time for customer's satisfactions. So, Allah will reward you because you are going behind the Islam attitudes".

"Quality management service is to be honest in your product, no cheating no lying, but has good standard quality because it is impossible to separate the process and the human factor. Quality, I believe, when built into a product, generates emotions and feelings within those who built it. When someone made something proud of, when he produce a product that brings smiles to customers, then someone have achieved quality. The person himself will know it and the others will know it, and both will prosper from it. Therefore, quality in Islam services is a fulfillment of expectation, is doing good things right and this is uniquely defined by each individual".

In addition another participant answered this question in a different way comparing with other answers and he said:
"Quality management services can be seen from this example. Most companies work are not related or based on Islamic perspective. They do their tasks without giving any attention whether these tasks are made according to Sharera'a or not. For example, the Bar selling alcohol this Bar provide a good services and the management of this Bar make sure that the customers are satisfy and all process happen in a good way that means it should be in high quality. While in reality all this work done does not related to Islam. So, my understanding to this question the quality services in Islam perspective should not related to all sectors".

As common known that some organisations may be trading in or selling in khamr or other haram products or services; hence, the conduct of the whole organisation is unethical but most of these organisations are implement quality management standards and provide good level of services (Beekun, 1981).

Based on what was being said above, all participants refer this question to the previous one which was related to quality management in Islam. But in this question they gave more detailed answer and explained their answers based on Qur'an and Sunnah.

\section{Conclusions and discussion}

The content analysis of the awareness of quality management services in Islam perspective was able to provide the information that was needed to answer our research questions. We were able to understand the people background related to this topic.

Based on the previous result from all participants that were interviewed, and all literature reviewed, we can say that the quality is a standards, and any organisation follow 
this standards will achieve the quality such as Edward Deming's establish fourteen points to reach the standard of quality and if any organisation implement these points will achieve quality and will be reward for any quality services. In Islam Prophet Mohammed (SAW) established the standards for all Muslims and if the Muslims follow these standards he/she will get reward from Allah.

This is clear evidence that the standard concept is not new concept it came from Islam and as participants were interviewed and base on the literature reviewed, we can find that the quality is the standard and the standard as we just discussed came from Islam. So, we can conclude that the quality came from Islam.

In addition, quality management services as most participants mentioned in the interviews were based on literature review. It provides unique services to satisfy the external customers rather than satisfy the internal customers which means the employees who are working in the organisation. The management in any organisation should manage the relationships with their customers is it critical to the firms long-term success (Beckett, 1998).

The positive relationships between external and internal customers can be found if the employees were satisfied with the external customers, because if the employees were satisfied they will be loyal to the organisation and can provide unique services. So, the employees should contact with customers in a good way. In any quality model the high degree of services is always given to the customer's satisfaction. The positive relationship is an organisation with customers, if not, it means organisations without profits.

And as Allah's Messenger (SAW) said, "Your smile before your brother is a sadaqah for you".

In addition, the Prophet Mohammed (SAW) said, 'The truthful trustworthy merchant is with the Prophet (SAW) the true ones and the martyrs (on the Day of Resurrection).

In present study, participants were interviewed to measure their awareness about the quality services in Islam perspective and who is the father (founder) of quality; Juran from the West and his popular ideas about quality or the Prophet Mohammed (SAW) and his ahead-of-time concepts. Many Arab countries are using the quality model, with many criteria and standards to improve the organisations (government and privets) without being aware that what they are implementing is quality's concept that originated from their own religion.

The unbelievable thing is that most of the organisations in the Arab world are trying to implement and translate the quality model created by the West. Sometimes, they find some difficulties translating the same exact method, which might result in poor and weaker outcomes.

On the other hand, implementing quality model based on Islamic values, which is already ready to use through the holy Qur'an and Sunnah, will result in a better result and stronger outcomes.

Based on interviews and literature review, we can conclude that the people need to be more aware about the quality management in Islam perspective and we can say, that there is a gap in this field and need to create new quality model based on Islam perspective. As a result, all people will be aware that the quality came from Islam and Prophet Mohammed (SAW) will be known as the father of quality. In my opinion, the quality existed before Islam, but with Islam quality, it became more complete. 


\section{References}

Ahmad, K. (2006) Management from Islamic Perspective, Research Center IIUM.

Al-Habshi, S.O. and Ghazali, A. (Eds.) (1994) Islamic Values and Management, IKIM, Kuala Lumpur.

Al-Habshi, S.O. and Hassan, N.M.E. (1998) Islam Knowledge and Ethics: A Pertinent Culture for Managing Organizations, Institute of Islamic Understanding Malaysia (IKIM), Perniagaan Rita, Kuala Lumpur.

Beckett, E.J. (1998) 'Integrating internal \& external customer's relationships through relationship management: a strategic response to a changing global environment', Virginia, Commonwealth University, UAE, June.

Beekun, R.I. (1981) Islamic Business Ethics, The International Institute of Islamic Thought.

Chakrapani, C. (1991) 'Deming's fourteen points and service quality research-1', Imprints, Magazine of the PMRS, July.

Faridi, F.R. (1997) Islamic Principles of Business Organization and Management, Institute of Objective Studies, S. Abdul Majeed \& CO., UtamaTiga, Kuala Lumpur, Malaysia.

Mohiuddin, M.G. (1997) Islamic and Scientific Management, Islami Foundation Patrica, Dhaka.

Shafi, M.M. (1980) Tafsir-e-maareful Quran, Islami Foundation, Dhaka, Bangladesh.

Stephens, K.S. and Juran, J.M. (2005) Quality, and Century of Improvement, American Society for Quality, Quality Press, Milwaukee, Vol. 15, ASQ 